\title{
An Adjusted Model for Simple 1,2-Dyotropic Reactions. Ab Initio MO and VB Considerations
}

\author{
Henk M. Buck \\ Kasteel Twikkelerf 94, Tilburg, The Netherlands \\ Email: h.m.buck@ziggo.nl
}

Received April 1, 2013; revised May 1, 2013; accepted June 1, 2013

Copyright (C) 2013 Henk M. Buck. This is an open access article distributed under the Creative Commons Attribution License, which permits unrestricted use, distribution, and reproduction in any medium, provided the original work is properly cited.

\begin{abstract}
With an adjusted model, we reconsider simple 1,2-dyotropic reactions with the introduction of a concept based on the intramolecular dynamics of a tetrahedron (van 't Hoff modeling). In fact the dyotropic reactions are strongly related to conversions originated from neighbouring group participation or anchimeric assistance, defined as the interaction of a center with a lone pair of electrons in an atom and the electrons present in a $\sigma$ or $\pi$ bond. The researchful 1,2-dyotropic reactions, based on the 1,2-interchange of halogens, methyl and hydrogen taking place in a concerted fashion, are in competition with the two-step reaction in which the neighbouring group participation or anchimeric assistance comes to full expression by ionic dissociation of the other exchangeable (halogen) atom. As to be expected there is an essential difference between halogen or methyl exchange regarding the number of electrons participating in the transition state. This aspect becomes evident in the geometries of the corresponding transition state geometries. In this paper we refer to ab initio $\mathrm{MO}$ calculations and VB considerations. We consider the 1,2-halogen exchange as a combination of two $\mathrm{S}_{\mathrm{N}} 2$ reactions each containing four electrons. The van 't Hoff dynamics appears a useful model in order to illustrate the computations in a straightforward manner.
\end{abstract}

Keywords: Type-I Dyotropic Reactions; MO Calculations; Van 't Hoff Model Considerations; Halogen and Methyl Exchange; Conflicting Models

\section{Introduction}

Recently a theoretical model has been given for type-I 1,2-dyotropic reactions of the type $\mathrm{CH}_{2} \mathrm{X}-\mathrm{CH}_{2} \mathrm{X}$ focused on the exchange of $\mathrm{X}$, based on sophisticated ab initio computations. Reactions of this type have been defined by Reetz as isomerizations that involve an intramolecular one-step migration of the two $\sigma$ bonds [1,2]. In type-I the shift is based on 1,2-interchange of atoms (halogens) or groups (methyl) that may result in inversion of configuration of the positions under consideration. We reconsider these identity reactions with the results based on a linear three-center four electron bonding, known as $\mathrm{S}_{\mathrm{N}} 2$ reactions in combination with van 't Hoff modeling $[3,4]$. We introduce an adjusted model for this type of exchange reactions. For the 1,2-interchange of dibromides, we will also focus the attention on a more complex system based on the mutarotation of $5 \alpha, 6 \beta$-dibromide cholestane that rearranges in the more stable diequatorial $5 \beta$, $6 \alpha$ isomer. In this situation, we are dealing with a more or less fixed geometry that disfavours the flexibility during the reaction course. We also take into consideration symmetry changes by substitution of $\mathrm{CH}_{2} \mathrm{X}-\mathrm{CH}_{2} \mathrm{X}$ for $\mathrm{SiH}_{2} \mathrm{X}-\mathrm{CH}_{2} \mathrm{X}$ and the corresponding dynamics.

\section{Results and Discussion}

\subsection{MO Calculations. Van 't Hoff Model Description for 1,2-Dyotropic Halogen Exchange Reactions in $\mathrm{CH}_{2} \mathrm{X}^{*}-\mathrm{CH}_{2} \mathrm{X}$ with $\mathrm{X}=\mathrm{F}, \mathrm{Cl}, \mathrm{Br}$, and $\mathrm{I}$. A Dibromide Isomerization in a More Complex and Rigid System}

The 1,2-dyotropic reactions we consider, are focused on identity halogen exchange in $\mathrm{CH}_{2} \mathrm{X}^{*}-\mathrm{CH}_{2} \mathrm{X}(\mathrm{X}=\mathrm{F}, \mathrm{Cl}$, $\mathrm{Br}$, and I). We also take notice of the results of hydrogen and methyl migration. The transition state (TS) is given in Figure 1.

The relevant $a b$ initio data for these exchange reactions are given in Table 1. These model calculations in combination with activation energies $\left(\Delta E^{\ddagger}\right)$ have been computed at ZORA-OLYP/TZ2P by Fernández et al. [5]. They also extended their studies to corresponding methyl and hydrogen shifts. We focus on the ratio 
$d[\mathrm{TS}, \mathrm{C}-\mathrm{X}] / d[\mathrm{R}(\mathrm{P}), \mathrm{C}-\mathrm{X}]$ based on the distances (d) indicated as $R(d)$, given in Table 1. The results in this table also demonstrate a linear relation between $\Delta E^{\ddagger}$ and $R(d)$. Similar observations have been done before and completely worked out [4].

We compare these results with the identity $\mathrm{S}_{\mathrm{N}} 2$ substitution reactions as given by

$$
\mathrm{X}^{-}+\mathrm{CH}_{3}-\mathrm{X} \rightarrow\left[\mathrm{X}-\mathrm{CH}_{3}-\mathrm{X}\right]^{-} \rightarrow \mathrm{X}-\mathrm{CH}_{3}+\mathrm{X}^{-} \text {. }
$$

The results are given in Table 2. For a qualification of the theoretical outcome we give the van 't Hoff model results. As we published before the van 't Hoff model is based on the transition from a regular tetrahedron into a trigonal pyramid (TP) by moving the tetrahedral carbon along the principal normal to the reaction center of the triangle [8]. In the $\mathrm{S}_{\mathrm{N}} 2$ reaction mechanism as originally proposed by Hughes and Ingold, the geometry of the TS then corresponds with a trigonal bipyramid (TBP) via backside attack of the incoming nucleophile, resulting in inversion of carbon [9]. We then arrive to:

$$
R(\cos \theta)=1-\cos \theta
$$

in which $\theta$ is the van 't Hoff tetrahedral angle. The value for $d[\mathrm{TS}, \mathrm{C}-\mathrm{X}]$ can then be expressed by:

$$
d[\mathrm{TS}, \mathrm{C}-\mathrm{X}]=R(\cos \theta) \times d[\mathrm{R}(\mathrm{P}), \mathrm{C}-\mathrm{X}]
$$

The ideal $R(\cos \theta)$ value is 1.333 with $\theta=109.47^{\circ}$

By comparison the ratio values $R(d)$ in Table 1 with the corresponding values in Table 2, it is clear that going from $\mathrm{Cl}$ to I there is a nearly constant difference. The average values are 1.263 and 1.298, respectively. However, it should be mentioned that the XCX angle in Figure 1 deviates from linearity for about $40^{\circ}$. The ratio value of 1.333 for $n=4$ can be intuitively obtained with:

$$
R(n)=1+n / 12
$$

in which $n$ is the number of electrons in the TS [3].

This relation has been tested for identity methyl, proton, hydrogen atom, and hydride exchange reactions in relation to three center four-(methyl cation and proton), three-(hydrogen atom), and two electrons (hydride anion) following the corresponding principal reaction coordinate in the TS $[3,8]$. The $R(n)$ values are then 1.333, 1.250, and 1.167. These values are in good correspondence with $a b$ initio values and the van 't Hoff model considerations. In the case of four electrons and a three center carbon configuration, hypervalency could be frozen as a TBP configuration reflecting nicely the 1.333 value $[3,4]$.The significance for proton transfer focused on biochemical networks could be clearly visualized with the van 't Hoff model making this and the other transfer reactions understandable in order to judge the computations [4].

From the description of the reaction type as proposed by Fernández et al. [5] under investigation, four $\sigma$ electrons are involved. This results in a ratio value of 1.167 for each $\mathrm{X}-\mathrm{C}-\mathrm{X}$ bonding, a value that differs strongly from the results in Table 1. Therefore the mechanism for this type of reactions as presented in Figure 1 in combination with the computational results in Table 1 must be considered from a model that includes an additional contribution of four electrons in the TS. These extra electrons can be delivered by one of the lone pairs of each transferred X. Summarizing, each X delivers two $\sigma$ electrons $(\mathrm{C}-\mathrm{X}$ bond $)$ and one lone pair. This electron

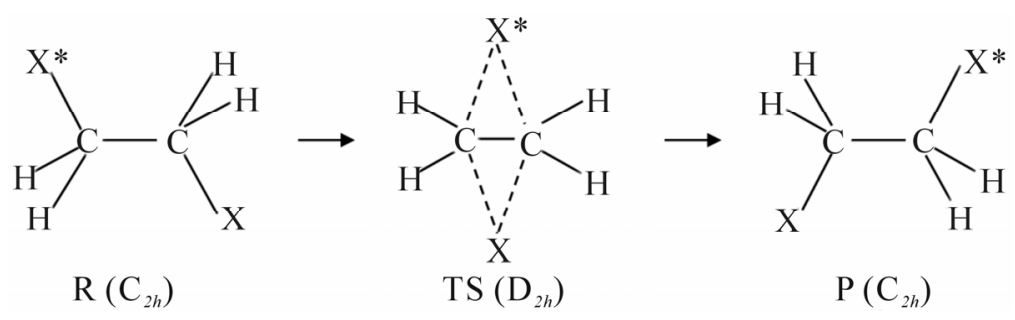

Figure 1. Reaction pathway for $\mathrm{CH}_{2} \mathrm{X}^{*}-\mathrm{CH}_{2} \mathrm{X} \rightarrow \mathrm{CH}_{2} \mathrm{X}-\mathrm{CH}_{2} \mathrm{X}^{*}$ with $\mathrm{X}=\mathrm{F}, \mathrm{Cl}$, Br, and I.

Table 1. Geometric values of distances (in $\AA$ ), angles (in deg) and activation energies $\left(\Delta E^{\ddagger}\right.$ in $\left.\mathrm{kcal}^{\mathrm{l}} \cdot \mathrm{mol}^{-1}\right)$ for the reaction pathway as given in Figure $1^{\text {a }}$.

\begin{tabular}{ccccccccc}
\hline $\mathrm{X}$ & $\mathrm{TS}, \mathrm{C}-\mathrm{X}$ & $\mathrm{R}(\mathrm{P}), \mathrm{C}-\mathrm{X}$ & $R(d)^{\mathrm{b}}$ & $\Delta E^{+}$ & $\mathrm{R}(\mathrm{P}), \mathrm{C}-\mathrm{C}$ & $\mathrm{TS}, \mathrm{C}-\mathrm{C}$ & $\mathrm{TS}, \mathrm{XCC}$ & $\mathrm{TS}, \mathrm{X}-\mathrm{X}$ \\
\hline $\mathrm{F}$ & 1.874 & 1.398 & 1.340 & 65.1 & 1.523 & 1.401 & 68.0 & 3.476 \\
$\mathrm{Cl}$ & 2.283 & 1.803 & 1.266 & 42.6 & 1.517 & 1.412 & 72.0 & 4.343 \\
$\mathrm{Br}$ & $2.444(2.510)^{\mathrm{c}}$ & $1.982(1.934)^{\mathrm{d}}$ & $1.233(1.298)$ & $32.0(28.0)^{\mathrm{c}}$ & 1.509 & $1.413(1.417)^{\mathrm{c}}$ & $73.2(73.6)^{\mathrm{c}}$ & 4.679 \\
$\mathrm{I}$ & 2.662 & 2.192 & 1.214 & 24.9 & 1.501 & 1.409 & 74.7 & 5.134 \\
\hline
\end{tabular}

${ }^{\mathrm{a}}$ The distances, angles and activation energies are derived from computations of Fernández et al., [5]; ${ }^{\mathrm{b}} R(d)=\mathrm{TS}, \mathrm{C}-\mathrm{X} / \mathrm{R}(\mathrm{P}), \mathrm{C}-\mathrm{X} ;{ }^{\mathrm{c}} \mathrm{Fernández}$ et al., [6]; ${ }^{\mathrm{d}} \mathrm{Ex}-$ perimental distance for $\mathrm{CH}_{3} \mathrm{Br}[7]$. 
participation connects the results of Tables 1 and $\mathbf{2}$ in demonstrating a rather good correspondence between the calculated distances and those obtained with the van 't Hoff model. In our opinion this electron participation in the TS model may be an effective model for explaining the 1,2-dyotropic halogen exchange reactions. Studying the effects of electron-donating (D) and electron-accepting (A) substituents for the hydrogens of the ethane moiety as (A)DXHC-CHXD(A), it appears that the electron-donating substituents reduce the $\Delta \mathrm{E}^{\neq}$in contrast with the acceptor substituents for the bromine exchange [6]. This aspect may be understandable by taken the $\mathrm{Br}-\mathrm{C}-\mathrm{Br}$ configuration. The displacement of the electrons from $\mathrm{C}$ to $\mathrm{Br}$ will be facilitated by donor substituents linked to carbon. This type of electron transfer has been calculated for the $\mathrm{S}_{\mathrm{N}} 2$ reactions with $\left[\mathrm{X}-\mathrm{CH}_{3}-\mathrm{X}\right]^{-}$as $\mathrm{TS}$. For $\mathrm{X}=\mathrm{Br}$ calculations give $q \mathrm{CH}_{3}=+0.188$ and $q \mathrm{Br}=-0.594$. This electron transfer decreases from $\mathrm{F}$ to $\mathrm{I}$ [7].

The reactions described are relatively simple in their geometry. Therefore we will consider a 1,2-exchange reaction for a more complex system as the diaxial $5 \alpha$, $6 \beta$-dibromide isomerization of cholestane into the stable diequatorial $5 \beta, 6 \alpha$-dibromide. This is illustrated in a simplified way in Figure 2. Both dibromides when treated with $\mathrm{NaI}$ in acetone undergo trans elimination with regeneration of cholestane in which the $5 \alpha, 6 \beta$-dibromide reacts much faster because the bromine and carbons all concerned lie in one plane and are in a favoured position for a four-center TS [9].
Calculations on the bromine exchange have been carried out by Fernández et al. for a simplified system (see Table 1) and the more complex system $5 \alpha, 6 \beta$ dibromocholestane. Because of the rigid structure of cholestane, there is a significant difference in the various distances in the TS [6]. The calculations give for the top $\mathrm{C}(5)-\mathrm{Br}=$ $2.766 \AA$ and $\mathrm{C}(6)-\mathrm{Br}=2.673 \AA$, and for the bottom $\mathrm{C}(5)-\mathrm{Br}=2.828 \AA$ and $\mathrm{C}(6)-\mathrm{Br}=2.540 \AA$. These data differ from the simple configuration as illustrated in Figure 1 with corresponding values for the bond length of $\mathrm{C}-\mathrm{Br}$ in the TS as given in Table 1 . The average value is $2.693 \AA$ corresponding with an $R(d)$ value of 1.392 and 1.359 for the experimental $\mathrm{C}-\mathrm{Br}$ distance of $1.934 \AA$ and the calculated value of $1.982 \AA$, respectively, as given in Table 1. These values are in good correspondence with the proposed van 't Hoff model as a realistic approach for the correctness of the ab initio calculations.

For the isomerization of the $5 \alpha, 6 \beta$ dibromocholestane also the activation parameters, as a first order in dibromide, were determined in chloroform [11]. These values are $\Delta H^{\neq}=19.9 \mathrm{kcal} \cdot \mathrm{mol}^{-1}, \Delta E^{+}=20.6 \mathrm{kcal} \cdot \mathrm{mol}^{-1}, \Delta S^{\neq}=$ $-14.3 \mathrm{cal} \cdot \mathrm{mol}^{-1} \mathrm{~K}^{-1}$, and $\Delta G^{\neq}=24.2 \mathrm{kcal} \cdot \mathrm{mol}^{-1}$. The value of $\Delta E^{\ddagger}$ can be compared with the values in Table 1 for the $\mathrm{D}_{2 h}$ symmetry. The negative value for $\Delta S^{\neq}$has been interpreted that fewer degrees of freedom are available than in the ground state which seems consistent with a dyotropic reaction. An ionization with internal return would show a positive value for $\Delta S^{\neq}$. In these considerations the nature of the medium may play an essential role. As has been proposed that a decrease in polarity

Table 2. Geometric values of distances (in $\AA$ ) for the reaction pathway of the exchange reaction $\mathrm{X}^{-}+\mathrm{CH}_{3}-\mathrm{X}_{\text {via a trigonal }}$ bipyramidal $\left[\mathrm{X}-\mathrm{CH}_{3}-\mathrm{X}\right]^{-}$transition state ${ }^{\mathrm{a}}$. A comparison with the van 't $\mathrm{Hoff}_{\text {model }}{ }^{\mathrm{b}}$.

\begin{tabular}{ccccccc}
\hline & \multicolumn{3}{c}{ ab initio } & \multicolumn{3}{c}{ Van 't Hoff } \\
\hline $\mathrm{X}$ & $\mathrm{R}(\mathrm{P}), \mathrm{C}-\mathrm{X}$ & $\mathrm{TS}, \mathrm{C}-\mathrm{X}$ & $R(d)^{\mathrm{c}}$ & $\mathrm{R}(\mathrm{P}), \mathrm{C}-\mathrm{X}^{\mathrm{d}}$ & $\mathrm{TS}, \mathrm{C}-\mathrm{X}$ & $R(\cos \theta)^{\mathrm{e}}$ \\
\hline $\mathrm{F}$ & 1.396 & 1.860 & 1.332 & 1.383 & 1.828 & 1.322 \\
$\mathrm{Cl}$ & 1.791 & 2.360 & 1.318 & 1.776 & 2.343 & 1.319 \\
$\mathrm{Br}$ & 1.959 & 2.510 & 1.281 & 1.934 & 2.522 & 1.304 \\
$\mathrm{I}$ & 2.157 & 2.720 & 1.261 & 2.132 & 2.812 & 1.319 \\
\hline
\end{tabular}

${ }^{\mathrm{a}}$ The $a b$ initio results are derived from computations of Bento et al. $[10]$; ${ }^{\mathrm{b}}$ The model results are obtained from the dynamics of a regular tetrahedron as originated by van 't Hoff into a trigonal bipyramid. See text; ${ }^{\mathrm{c}} R(d)=\mathrm{TS}, \mathrm{C}-\mathrm{X} / \mathrm{R}(\mathrm{P}), \mathrm{C}-\mathrm{X} ;{ }^{\mathrm{d}}$ The experimental distances are derived from $\mathrm{CH} \mathrm{H}_{3} \mathrm{X}[7]$; ${ }^{\mathrm{e}} R(\cos \theta)=1-\cos \theta$ in which $\theta$ is the experimental tetrahedral angle $\mathrm{HCX}$ in $\mathrm{CH}_{3} \mathrm{X}$ [7].

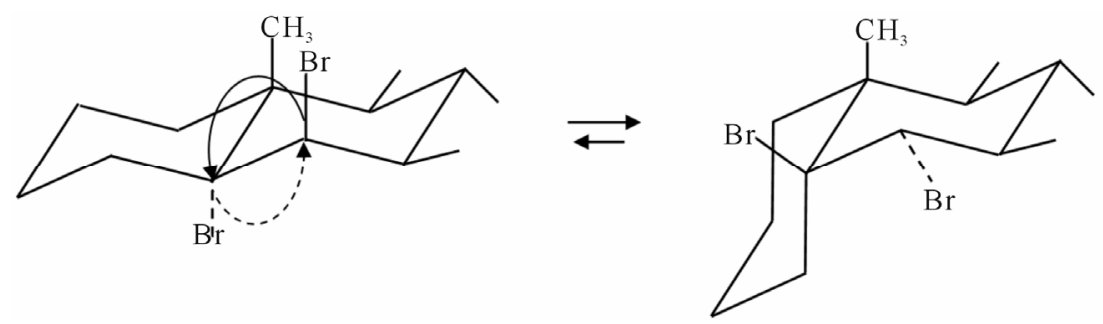

Figure 2. A simplified model for the isomerization of $5 \alpha, 6 \beta$ dibromocholestane in the corresponding $5 \beta, 6 \alpha$ isomer. 
will favour an intermediate or TS in which negligible charge separation is involved favouring a dyotropic reaction $[11,12]$.

\subsection{VB Considerations. Van 't Hoff Model Description for 1,2-Dyotropic Halogen Exchange Reactions. The Influence of the $\mathrm{C}-\mathrm{C}$ Bonding on the Electron Distribution in the $\mathrm{X}-\mathrm{C}-\mathrm{X}$ Transition State}

An instructive visualization of the TS with four electrons has been given in Figure 3.

This configuration shows an explicit contribution of two electrons for the formation of a double bond character of the $\mathrm{C}-\mathrm{C}$ bonding. The $\mathrm{MO}$ calculations show an average value of $1.409 \AA$ for $\mathrm{X}=\mathrm{F}(1.401 \AA), \mathrm{Cl}(1.412$ $\AA), \operatorname{Br}(1.413 \AA)$, and I (1.409 $\AA)$, resulting in a partial double bond character for the $\mathrm{C}-\mathrm{C}$ bonding. Expressed in bond orders with the corresponding number of electrons in parenthesis, we then calculate $0.626(1.252 \mathrm{e}), 0.560$ (1.120 e), 0.554 (1.108 e), and 0.578 (1.156 e), respectively. With the expression of $R(n)$, vide supra, we then obtain $1.281,1.287,1.287$, and 1.285 respectively, based on eight electrons with $4-q / 2$ electrons per $\mathrm{X}-\mathrm{C}-\mathrm{X}$ configuration in which $q$ is the electron density of the partial $\mathrm{C}-\mathrm{C}$ double bond. The $R(n)$ values are in correspondence with the average value of $R(d)$ i.e. 1.263 in Table 1, taking into account the deviation from linearity. Using the van 't Hoff model for the equatorial bonding, then:

$$
R(\sin \theta)=\sin \theta
$$

The value for $d[\mathrm{TS}, \mathrm{C}-\mathrm{C}]$ can then be expressed by:

$$
d[\mathrm{TS}, \mathrm{C}-\mathrm{C}]=R(\sin \theta) \times d[\mathrm{R}(\mathrm{P}), \mathrm{C}-\mathrm{C}]
$$

With the tetrahedral XCC angles $107.68^{\circ}, 109.79^{\circ}$, $109.61^{\circ}, 109.93^{\circ}$, respectively, we obtain for $d$ [TS, C-C] the corresponding values $1.451 \AA, 1.427 \AA, 1.421 \AA$, and $1.411 \AA$. There is significant deviation from the $\mathrm{C}-\mathrm{F}$ distance of $1.401 \AA$ as given in Table 1. From these considerations it is clear that the TS geometry of these type of reactions must described by eight electrons and not by four electrons as was supposed. Therefore it is of interest to take notice of the methyl exchange reactions instead of

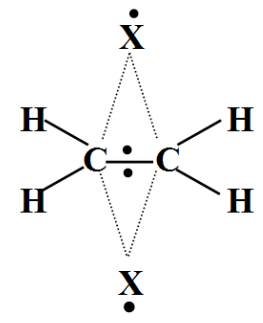

Figure 3. A characteristic VB configuration for a dyotropic reaction of 1,2-X exchange. halogen. In that case we are not dealing with extra electrons as in the case of the additional lone pairs of the halogens. The results will be discussed in the next section.

\subsection{MO Calculation. Van 't Hoff Model for 1,2-Dyotropic Methyl Exchange Reactions}

From the $a b$ initio calculations it is clear that the $\mathrm{C}-\mathrm{C}$ bond distance in the TS $(1.350 \AA)$ is very close to the ethylenic bond, corresponding with 1.859 e. Since no extra electrons are available, only via hyperconjugation of the methyl group, we calculated that only $1.071 \mathrm{e}$ remains for each $\mathrm{H}_{3} \mathrm{C}-\mathrm{C}-\mathrm{CH}_{3}$ configuration. This result has no physical meaning in a three-center bonding. Apparently, we are dealing with a different TS complex than in the case of halogen exchange. In our opinion, Figure 3 is a good representation. It is clear that in this case we are approaching a dissociative TS. A similar conclusion can be drawn for a corresponding 1,2-hydrogen exchange reaction. For a better understanding of the different TS complexes of the halogen and methyl exchange reactions it is obvious to consider halogen and methyl migration at one side of the $\mathrm{C}-\mathrm{C}$ linkage. At first we will discuss the 1,2-methyl migration with cornerprotonated cyclopropane [13]. As to be expected the corner-protonated cyclopropane, which can be considered as an intermediate in this methyl migration, is closely related to the stable nonclassical 2-norbornyl cation. The distances based on the triangle $\mathrm{CXC}$, in which $\mathrm{X}=\mathrm{CH}_{3}$, are $\mathrm{C}-\mathrm{C} 1.399 \AA$ (1.394 $\AA$ ) and $\mathrm{C}-\mathrm{CH}_{3}$ $1.803 \AA(1.829 \AA)$, corresponding values for the nonclassical 2-norbornyl cation are given in parenthesis [14]. Comparison of the geometry of the corner-protonated cyclopropane with the structure in Figure 3 for $\mathrm{X}=\mathrm{CH}_{3}$, then there is with respect to the former one a decrease in CXC angle of $13.94^{\circ}$, a decrease in $\mathrm{C}-\mathrm{C}$ bond distance of $0.049 \AA(3.50 \%)$ and an increase in $\mathrm{C}-\mathrm{X}$ distance of $0.667 \AA(36.99 \%)$. This dramatic increase in $\mathrm{C}-\mathrm{X}$ bond length in the 1,2-methyl migration asks for a similar analysis of the corresponding halonium geometries. These halonium ions are known in the triangle geometry as has been established from the NMR work of Olah et al. [15]. We also mention a stable bromonium ion in the reaction of adamantylideneadamantane with bromine by Strating et al. [16]. The MO results are given in the next section.

\subsection{A Comparison between the MO Results of the 1,2-Cyclic Halonium Ion and the Transition State of 1,2-Dyotropic Halogen Exchange}

A coordinate halonium structure of the halogen exchange is given in Figure 4. 
However, this intermediate follows a classical twostep mechanism resulting in the same stereochemistry as the one-step 1,2-dyotropic halogen exchange reaction. As starting point for the reaction profile a $\mathrm{C}_{2 h}$ symmetry ( $\mathrm{R}$, $\mathrm{P})$ is selected. Via a conrotatory process, both halogens reach a geometry that demonstrates a TP configuration in which the central carbon is in-plane with $2 \mathrm{H}$ 's and the other $\mathrm{CH}_{2}$ group, and the halogen is located in the axial position of the TP. From UV-vis and NMR spectroscopic measurements in combination with $\mathrm{MO}$ calculations based on model systems as the proton complexes of 1 , 1-diphenyl-2-halogeno $(\mathrm{Cl}, \mathrm{Br}$, and $\mathrm{I})$ ethylenes with para electron-donating substituents:

$$
\mathrm{Ar}_{2} \mathrm{C}(1)^{+}-\mathrm{C}(2) \mathrm{H}_{2} \mathrm{X}(\mathrm{X}=\mathrm{Cl}, \mathrm{Br} \text {, and } \mathrm{I})
$$

in which $\mathrm{Ar}$ is the aryl group with para substituents as $\mathrm{OCH}_{3}$ and $\mathrm{N}\left(\mathrm{CH}_{3}\right)_{2}$, a TP geometry has been proposed for $\mathrm{C}(2)$ as center in plane of the triangle formed by $\mathrm{C}$ (1) and the $2 \mathrm{H}$ 's with $\mathrm{X}$ in a $\mathrm{C}(2)-\mathrm{X}$ axial position $[17,18]$. With MO symmetry arguments related to the twofold axis of symmetry of the carbenium ions, the A HOMO$S$ LUMO transition appears a good criterion for determining the electron shift from $\mathrm{C}(2)$ to $\mathrm{X}$. Generally for a good fit between the UV-vis and NMR spectroscopy with the MO calculations, a shift of about 0.6 e has been taken place in the direction of $\mathrm{X}$ for the $\mathrm{C}(2)-\mathrm{X}$ bonding. A similar exclusive shift is absent for $\mathrm{C}(2)-\mathrm{F}$. In that case the dominant electronegativity of $\mathrm{F}$ has already depleted the $C(2)$ electron density in the tetrahedral configuration that cancels change in hybridization from $s p^{3}$ into $s p^{2}$ [18]. Summarizing, the TP model is valid for $\mathrm{Cl}$, $\mathrm{Br}$ and $\mathrm{I}$ whereas $\mathrm{F}$ preserves its tetrahedral configuration in the bonding with $\mathrm{C}(2)$.

Furthermore from other data it is well known that $\mathrm{F}$ is not able to form a triangle halonium ion [15]. After reaching this location on the reaction coordinate, there is an inversion of charge on the halogen by coordination with the other carbon of the ethane linkage. The reaction then proceeds via $D_{2 h}$ symmetry as shown in Figure 3. The differences in geometry between the corner-protonated cyclopropane and the 1,2-dyotropic methyl exchange TS are much more pronounced than the corresponding geometric differences between the halonium ions [19] and the 1,2-dyotropic halogen TS. For the CXC

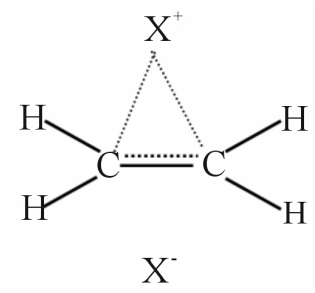

Figure 4. A coordinate halonium structure of the 1,2-dyotropic reaction. angle, the decrease is $9.84^{\circ}(\mathrm{Cl})$ and $6.34^{\circ}(\mathrm{Br})$. The increase for the $\mathrm{C}-\mathrm{X}$ distance is $0.407 \AA(21.70 \%, \mathrm{Cl})$ and $0.335 \AA(15.88 \%, \mathrm{Br})$. The differences for the $\mathrm{C}-\mathrm{C}$ bond length are of minor significance. This explains the fundamental distinction between the methyl and halogen exchange reactions.

The position of $\mathrm{F}$ on the energy profile is now also clear. In the $1,2-\mathrm{F}$ migration $\Delta E^{\neq}\left(65.1 \mathrm{kcal} \cdot \mathrm{mol}^{-1}\right)$ is much higher than for the corresponding halogens $(\mathrm{Cl}$ $42.6 \mathrm{kcal} \cdot \mathrm{mol}^{-1}$, Br $32.0 \mathrm{kcal} \cdot \mathrm{mol}^{-1}$, and I $24.9 \mathrm{kcal}$. $\mathrm{mol}^{-1}$ ). Accommodation of positive charge on $\mathrm{F}$ in comparison with the other halogens is in fact an unfavourable model for double migration. Although the locations on the energy profile are focused on the interaction of one of the lone pairs halogens with the other carbon of the $\mathrm{C}-\mathrm{C}$ linkage, there may be another profile for the 1,2-F migration.

The contrast between $\mathrm{F}$ and the other halogens is clear. For the geometries in Figure 1, the following $\mathrm{CXC}$ bond angles were calculated $43.90^{\circ}(\mathrm{X}=\mathrm{F}), 36.02^{\circ}(\mathrm{X}=\mathrm{Cl})$, $33.61^{\circ}(\mathrm{X}=\mathrm{Br})$, and $30.69^{\circ}(\mathrm{X}=\mathrm{I})$. A similar behaviour is found for the open structures of the dialkylhalonium ions $\left[\mathrm{H}_{3} \mathrm{C}-\mathrm{X}-\mathrm{CH}_{3}\right]^{+}$. The calculations show for the $\mathrm{CXC}$ bond angles $120.2^{\circ}(\mathrm{X}=\mathrm{F}), 105.0^{\circ}(\mathrm{X}=\mathrm{Cl})$, $101.4^{\circ}(\mathrm{X}=\mathrm{Br})$, and $97.7^{\circ}(\mathrm{X}=\mathrm{I})$. The cations for $\mathrm{X}=$ $\mathrm{Cl}, \mathrm{Br}$, and $\mathrm{I}$ have been prepared as long-lived cations. However, no stable dialkylfluoronium ion has been obtained [20]. The exclusive electronegativity of $\mathrm{F}$ with respect to the other halogens determines the expansion of the XCX angle. For simplicity it means that $\mathrm{F}$ aims at an increase of its $s$ character. In that respect it is of interest to mention the results of the calculations of methylated dimethylhalonium ions. Theoretically it has been found that methylated dimethylhalonium ions accommodate a tetrahedral configuration whereas $\left[\left(\mathrm{CH}_{3}\right)_{3} \mathrm{~F}\right]^{2+}$ has a $\mathrm{D}_{3 h}$ symmetry [20]. Thus by going from $\mathrm{C}_{3 v}$ to $\mathrm{D}_{3 h}$ symmetry, F increases its $s$ character.

Recently, there was mechanistic evidence for a symmetrical intermediate in solution [21]. The CFC bond angle and the $\mathrm{C}-\mathrm{F}$ distance calculated from this fluoronium ion derived from a fixed configured precursor, correspond with the values as given for the $\left[\mathrm{H}_{3} \mathrm{C}-\mathrm{F}-\mathrm{CH}_{3}\right]^{+}$ion [20].

\subsection{A Comparison of $1,2-\mathrm{SiH}_{3}$ and $\mathrm{CH}_{3}$ Shifts as Substituents in Ethane. MO Calculations and Van't Hoff Model Consideration}

We consider reactions as illustrated in Figure 1 in which $\mathrm{X}=\mathrm{SiH}_{3}$. Like $\mathrm{CH}_{3}$, Si has not the capacity to deliver extra electrons. So it is to be expected that the geometry for the TS of the $\mathrm{SiH}_{3}$ shift is in correspondence with the methyl shift. In fact it means that two electrons are available for each $\mathrm{H}_{3} \mathrm{Si}-\mathrm{C}-\mathrm{SiH}_{3}$ configuration. This elec- 
tron participation results in conflicting values for $R(n)$ and $R(d)$. In order to escape this split, the TS can be described as given in Figure 3. This is in excellent agreement with the ethylenic bond distance of $1.354 \AA$ corresponding with $1.81 \mathrm{e}$. This geometry involves a dissociative state. The calculations show that the $\Delta E^{f}$ for the $\mathrm{SiH}_{3}$ shift $\left(101.7 \mathrm{kcal} \cdot \mathrm{mol}^{-1}\right)$ is smaller than for the $\mathrm{CH}_{3}$ shift $\left(131.0 \mathrm{kcal} \cdot \mathrm{mol}^{-1}\right)$. This aspect can be qualitatively explained by orbital expansion of Si compared with carbon.

\subsection{Symmetry Change in the 1,2-Dyotropic Halogen Exchange Reactions}

Changing the $\mathrm{C}-\mathrm{C}$ linkage through $\mathrm{Si}-\mathrm{C}$ is of interest in consequence of loss of its symmetry and an increasing coordination ability of Si compared with carbon [5]. This aspect is observable for the 1,2-F migration between $\mathrm{Si}$ and carbon. In that specific case there is a pronounced asymmetry in F shift as follows from the different angles in the triangle $\mathrm{CSiF} 76.31^{\circ}, \mathrm{SiCF} 50.39^{\circ}$, and $\mathrm{CFSi}$ $53.30^{\circ}$. For comparison the corresponding results are given for the symmetric TS of the 1,2-exchange reaction of the 1,2-disubstituted fluoroethane i.e., FCC $68.04^{\circ}$ and CFC 55.98 . Thus in the asymmetric TS the deviation from linearity is substantially decreased compared with the symmetric one. This aspect is recognized in $\Delta E^{\neq}$. For the asymmetric TS $48.9 \mathrm{kcal} \cdot \mathrm{mol}^{-1}$ has been calculated whereas for the symmetric TS $65.1 \mathrm{kcal} \cdot \mathrm{mol}^{-1}$ is found. It involves that $\mathrm{Si}$ accommodates a fifth ligand easier than carbon with a geometry closely related to a TBP configuration that results in lowering of the $\Delta E^{f}$ of the TS [22]. This aspect is also reflected in the value of $R(d)$ for the $\mathrm{Si}-\mathrm{F}$ bond in the transition intermediate that approaches its normal bond length. However, for coordination of the other $\mathrm{F}$ with $\mathrm{Si}$ the displacement of $\mathrm{F}$ is considerable, resulting in a high $R(d)$ value of 1.582 for the $\mathrm{C}-\mathrm{F}$ bond that influences the transition for the 1,2-F migration in a negative manner. In the corresponding 1,2disubstituted chloroethane, the difference between the angles $\mathrm{CSiCl}$ and $\mathrm{SiCCl}$ is $7.21^{\circ}$ whereas in the former one a value of $25.92^{\circ}$ is found. The $R(d)$ values of $\mathrm{Si}-\mathrm{Cl}$ and $\mathrm{C}-\mathrm{Cl}$ are 1.212 and 1.353 , respectively with an average value of 1.283. This value is in correspondence with the average value of 1.309 of the fluorine exchange. This difference is also reflected in the $\Delta E^{\neq}$values. The 1,2- $\mathrm{Cl} \mathrm{mi-}$ gration is $9.8 \mathrm{kcal} \cdot \mathrm{mol}^{-1}$ in favour over the $1,2-\mathrm{F}$ exchange.

\section{Conclusion}

It has been suggested that type-I 1,2-dyotropic reactions as presented in this paper are considered as four-membered transition states, involving a concerted exchange migration of the $\mathrm{X}$ atoms or groups in $\mathrm{CH}_{2} \mathrm{X}-\mathrm{CH}_{2} \mathrm{X}$. The discussion is based on $\mathrm{X}=$ halogen, methyl and hydrogen.
According to our results there is a fundamental difference in the description of this dyotropic reaction with others concerning the participation of the number of electrons in the TS based on a clear distinction between the halogen and the methyl and hydrogen exchange. The difference is clear. The halogen exchange takes profit from the presence of its lone pair electrons. This "catalyzing" effect is absent for methyl and hydrogen exchange, explaining the relatively high $\Delta E^{\ddagger}$ values of 131.0 and $145.2 \mathrm{kcal} \cdot \mathrm{mol}^{-1}$, respectively, in comparison with the halogens as shown in Table 1. A similar effect is found for the $R(d)$ values of 1.613 and 1.697, respectively, compared with the $R(d)$ values of the halogens in Table 1. The differences between methyl and hydrogen migration as expressed in $\Delta E^{f}$ and $R(d)$ are in fact a measure for the effect of hyperconjugation of the methyl group in the exchange reaction. The high values for both $R(d)$ 's of the methyl and hydrogen binding in the TS (much higher than the van 't Hoff value of 1.333) are an indication for a loose complex binding or a dissociative state as illustrated in Figure 3 and is confirmed by the distance of the $\mathrm{C}-\mathrm{C}$ bond that approaches the double bond character. The effect of the $\mathrm{SiH}_{3}$ transfer is still more explicit compared with the $\mathrm{CH}_{3}$ migration, resulting in a decrease in $\Delta E^{\neq}$value of $29.3 \mathrm{kcal} \cdot \mathrm{mol}^{-1}$ as a result of Si-orbital expansion. Generally, there is a strict linear relation between $\Delta E^{\neq}$and $R(d)$ for the halogen exchange. This relation is supported by definition that for $\Delta E^{\neq}=a+b \times R(d)$ then must apply $a+b=0$ which has been established. The methyl and hydrogen shift deviates from the halogen linearity. Finally, it is our conclusion that the mechanistic view of Fernández et al. [5] based on a qualitative VB analysis as given in Figure 3 is far from complete. However, this approach is usable for the methyl and hydrogen exchange because of its reduced tendency for bonding in consequence of the available electrons in the transition state. In fact the differences in the 1,2-X migration are based on the overall number of electrons participating in the transition state. This situates the halogens with their additional lone pairs in a complete different position as methyl and hydrogen.

\section{REFERENCES}

[1] M. T. Reetz, "Dyotropic Rearrangements, a New Class of Orbital-Symmetry Controlled Reactions. Type I," Angewandte Chemie International Edition in English, Vol. 11, No. 2, 1972, pp. 129-130. doi:10.1002/anie.197201291

[2] I. Fernández, F. P Cossío and M. A. Sierra, "Dyotropic Reactions: Mechanisms and Synthetic Applications," Chemical Reviews, Vol. 109, No. 12, 2009, pp. 6687-6711. doi:10.1021/cr900209c

[3] H. M. Buck, "A Combined Experimental, Theoretical, and Van 't Hoff Model Study for Identity Methyl, Proton, Hydrogen Atom, and Hydride Exchange Reactions. Cor- 
relation with Three-Center Four-, Three-, and Two-Electron Systems," International Journal of Quantum Chemistry, Vol. 108, No. 9, 2008, pp. 1601-1614.

doi:10.1002/qua.21683

[4] H. M. Buck, "A Linear Three-Center Four Electron Bonding Identity Nucleophilic Substitution at Carbon, Boron, and Phosphorus. A Theoretical Study in Combination with Van 't Hoff Modeling," International Journal of Quantum Chemistry, Vol. 110, No. 7, 2010, pp. 14121424. doi:10.1002/qua

[5] I. Fernández, F. M. Bickelhaupt and F. P. Cossío, "Type-I Dyotropic Reactions: Understanding Trends in Barriers," Chemistry-A European Journal, Vol. 18, No. 39, 2012, pp. 12395-12403. doi:10.1002/chem.201200897

[6] I. Fernández, M. A. Sierra and F. P. Cossío, "Stereoelectronic Effects on Type I 1,2-Dyotropic Rearrangements in Vicinal Dibromides," Chemistry-A European Journal, Vol. 12, No. 24, 2006, pp. 6323-6330. doi:10.1002/chem.200501517

[7] M. N. Glukhovtsev, A. Pross and L. Radom, "Gas-Phase Identity $\mathrm{S}_{\mathrm{N}} 2$ Reactions of Halide Anions with Methyl Halides. A High-Level Computational Study," Journal of the American Chemical Society, Vol. 117, No. 7, 1995, pp. 2024-2032. doi:10.1021/ja00112a016

[8] H. M. Buck, "A Model Investigation of Ab Initio Geometries for Identity and Nonidentity Substitutions with ThreeCenter Four- and Three-Electron Transition States," International Journal of Quantum Chemistry, Vol. 111, No. 10, 2011, pp. 2242-2250. doi:10.1002/qua.22529

[9] T. H. Lowrey and K. S. Richardson, "Mechanism and Theory in Organic Chemistry," Harper \& Row, New York, 1976.

[10] A. P. Bento and F. M. Bickelhaupt, "Nucleophilicity and Leaving-Group Ability in Frontside and Backside $\mathrm{S}_{\mathrm{N}} 2$ Reactions," The Journal of Organic Chemistry, Vol. 73, No. 18, 2008, pp. 7290-7299. doi:10.1021/jo801215z

[11] D. H. R. Barton and A. J. Head, "Long-Range Effects in Alicyclic Systems. Part I. The Rates of Rearrangement of Some Steroidal Dibromides," Journal of the Chemical Society, 1956, pp. 932-937. doi:10.1039/jr9560000932

[12] C. A. Grob and S. Winstein, "Mechanismus der Mutarotation von 5, 6-Dibromcholestan," Helvetica Chimica Acta, Vol. 35, No. 3, 1952, pp. 782-802. doi:10.1002/hlca.19520350315

[13] L. Radom, J. A. Pople, V. Buss and P. V. R. Schleyer, "Molecular Orbital Theory of the Electronic Structure of Organic Compounds. XI. Geometries and Energies of $\mathrm{C}_{3} \mathrm{H}_{7}$ Cations," Journal of the American Chemical Society, Vol. 94, No. 2, 1972, pp. 311-321. doi:10.1021/ja00757a001

[14] P. R. Schreiner, D. L. Severance, W. L. Jorgensen, P. von Schleyer and H. F. Schaefer III, "Energy Difference between the Classical and the Nonclassical 2-Norbornyl Cation in Solution. A Combined Ab Initio-Monte Carlo Aqueous Solution Study," Journal of the American Chemical Society, Vol. 117, No. 9, 1995, pp. 2663-2664. doi:10.1021/ja00114a037

[15] G. A. Olah, G. K. S. Prakash, Á. Molnár and J. Sommer, "Superacid Chemistry," 2nd Edition, John Wiley \& Sons, Inc., Hoboken, 2009. doi:10.1021/ja00114a037

[16] J. Strating, J. H. Wieringa and H. Wynberg, "The Isolation of a Stabilized Bromonium Ion," Journal of the Chemical Society D Chemical Communications, No. 16, 1969, pp. 907-908.

[17] H. M. Buck, "Mechanistic Models for the Intramolecular Hydroxycarbene-Formaldehyde Conversion and Their Intermolecular Interactions: Theory and Chemistry of Radicals, Mono-, and Dications of Hydroxycarbene and Related Configurations," International Journal of Quantum Chemistry, Vol. 112, No. 23, 2012, pp. 3711-3719. doi:10.1002/qua.24127

[18] H. M. Buck, "Trigonal Pyramidal Carbon Geometry as Model for Electrophilic Addition-Substitution and Elimination Reactions and Its Sinificance in Enzymatic Processes," International Journal of Quantum Chemistry, Vol. 107, No. 1, 2007, pp. 200-211. doi:10.1002/qua.21061

[19] D. F. Shellhamer, D. C. Gleason, S. J. Rodriguez, V. L. Heasley, J. A. Boatz and J. J. Lehman, " Correlation of Calculated Halonium Ion Structures with Product Distributions from Fluorine substituted Terminal Alkenes," Tetrahedron, Vol. 62, No. 50, 2006, pp. 11608-11617. doi:10.1016/j.tet.2006.09.071

[20] G. A. Olah, G. Rasul, M. Hachoumy, A. Burrichter and G. K. S. Prakash, " Diprotonated Hydrogen Halides $\left(\mathrm{H}_{3} \mathrm{X}^{2+}\right)$ and Gitonic Protio Methyl- and Dimethylhalonium Dications $\left(\mathrm{CH}_{3} \mathrm{XH}_{2}{ }^{2+}\right.$ and $\left.\left(\mathrm{CH}_{3}\right)_{2} \mathrm{XH}^{2+}\right)$. Theoretical and Hydrogen-Deuterium Exchange Studies," Journal of the American Chemical Society, Vol. 122, No. 12, 2000, pp. 2737-2741. doi:10.1021/ja994044n

[21] M. D. Struble, M. T. Scerba, M. Siegler and T. Lectka, "Evidence for a Symmetrical Fluoronium Ion in Solution," Science, Vol. 340, No. 6128, 2013, pp. 57-60. doi:10.1126/science.1231247

[22] A. Streitwieser Jr. and C. H. Heathcock, "Introduction in Organic Chemistry," 3rd Edition, Macmillan Publishing Company, New York, 1985. doi:10.1126/science. 1231247 